\title{
Moving safely at night? Women's nocturnal mobilities in Recife, Brazil and Brussels, Belgium
}

\author{
Leila Farina, Kobe Boussauw \& Anna Plyushteva
}

Farina, L., Boussauw, K., \& Plyushteva, A. (2021). Moving safely at night? Women's nocturnal mobilities in Recife, Brazil and Brussels, Belgium. Gender, Place \& Culture, in press.

https://doi.org/10.1080/0966369X.2021.1937064

\section{Abstract}

This paper examines the links between women's un/safety and their night-time mobilities in Brussels, Belgium and Recife, Brazil. While the significance of women's intersectional identities to the construction of fear and safety in urban space has been well documented in feminist urban geography, we argue that the lens of South-North comparison highlights specific ways in which local urban spaces are implicated in women's experiences of un/safety. A comparative perspective draws out the spatial and temporal embeddedness of un/safety, while at the same time challenges the framing of particular cities and areas as either safe or unsafe (which is particularly damaging when it reproduces simple global North global South binaries). The paper draws on mixed-method research combining a questionnaire-based survey and a series of interviews with women in Recife and Brussels. The four dimensions examined include transport modes; situated experiences of un/safety; the accumulation of unsafety feelings over the long term; and the work women perform in maintaining mobility. We find that while unsafety broadly limits women's access to cities at night, feeling unsafe plays out differently in specific and situated interactions, many of which are recognisable from both Brussels and Recife. Across the two research locations, women's mobility strategies at night are similar, in that they involve extensive planning, preparation, and drawing on financial and non-financial resources. We conclude with some reflections on the role of comparative research in the feminist geographies of gendered urban mobilities, particularly in relation to previously little-studied cities.

Keywords:

gendered mobilities; women; night-time mobility; feelings of unsafety; comparative research

\section{Introduction}

For many women living in cities, the night is a timespace of distinctive im/mobilities. Across many urban contexts, one of the key barriers to nocturnal mobility is worrying for one's safety (Loukaitou-Sideris and Fink 2009; Schmucki 2012; Parikh 2018). While fearing to move around cities after dark is an experience both men and women recognise, the ways in which feelings of unsafety shape mobility and vice-versa are unmistakably gendered (as well as racialised and classed; see Kern 2005). Feminist urban geographies have long since overcome simplistic framings of these interconnections as either oppressive or liberating for women (see Bondi and Rose 2003; Wilson 2001). However, geographical understandings of the entanglements of mobility and immobility (each encompassing constraints as well as 
choices), the city's diurnal rhythms, and women's complex identities, remain partial (Pratt and Hanson 1994). We advance this work by drawing on the conceptual potential of comparison, thus enriching a research field which by virtue of its in-depth, qualitative engagement with women's experiences, is often reliant on single locations and methods.

The present paper takes a comparative and multi-method approach to women's nocturnal mobilities, spanning, and interrogating, the South-North divide (see Murray, Sawchuk, and Jirón 2016). This wider geographical angle inevitably also introduces limitations, in our case particularly in relation to insights into race and class. While we highlight how women's nighttime mobilities are embedded in situated and embodied experiences in particular urban locales, we also draw attention to meanings and practices which are shared across the two cities, notably in relation to the work which women in the two cities perform in order to feel safer at night. This allows us to complicate prevalent designations of particular cities as either safe or unsafe, notably along the global South - global North binary. Where transport research, including studies focused on gender, often examines constraints such as unsafety and unaffordability in separate silos, drawing on feminist urban scholarship enables us to examine these concerns in terms of gendered intersections (Datta and Ahmed 2020; Jirón, Carrasco, and Rebolledo 2020).

In the following sections, we first review the existing literature on the urban night, experiences of vulnerability and unsafety, and women's urban mobilities. We then introduce the two research locations, and the research methods used in data collection and analysis. The main body of the paper brings together the results from both cities, organized along four themes: transport modes and reasons for using them; feelings of unsafety in relation to specific journeys, settings, and interactions; constructing feelings of unsafety over the longer term; and the work of feeling safer. We conclude with a discussion of the implications of our findings, specifically in relation to comparative research in feminist urban geography across the North-South divide.

\section{Conceptual framework}

\subsection{Night-time mobility and feelings of unsafety}

In recent years, the number of studies focusing on the urban night has increased. Prominent topics include: the role of alcohol consumption (Eldridge and Roberts 2008), urban lighting (Boyce et al. 2000), the night-time economy (Bianchini 1995; Shaw 2014), and nightlifespecific policy making (van Liempt 2015; Smeds, Adam and McArthur 2020). However, the gendered experiences of participating in the urban night, particularly through differentiated access to night-time mobility, have received less attention (cf. Schmucki 2012; Collectiu Punt 6 2017; Parikh 2018; Plyushteva and Boussauw 2020).

The urban night is a distinctive timespace of reduced visibility, of possibilities and dangers of transgression, and increased fearfulness often associated with darkness (Williams 2008). In terms of physical mobility, the limiting impact of feeling unsafe after dark is compounded by fewer transport options, longer wait times, absence of people, and higher costs (Kern 2005; Collectiu Punt 6 2017). Thus, although feelings of unsafety are not unique to the night-time, they are distinctive and amplified in the hours of darkness.

While criminological and urban planning studies have aimed to trace feelings of unsafety to specific antecedents in criminal behaviours and/or the built environment, such causal links are 
not the main focus of the present paper. In focusing on women's experiences of un/safety, we aim to counter distinctions between objective reasons and subjective perceptions in conceptualising gendered experiences of unsafety (what has been referred to as women's 'fear paradox,' see, in particular, Koskela 1997 and Mehta and Bondi 1999). We thus set aside the question of whether feeling unsafe is 'justified' by the presence of 'real' threats. Taking the experiences of un/safety themselves as our starting point, we aim to explore the very real impacts which feeling unsafe has on nocturnal mobility, and the manner in which these impacts are gendered, recognisable to women in many different locations worldwide, as well as situated in specific settings and interactions.

\subsection{Women's mobilities}

Originally focusing on women's distinctive mobility patterns (which are often more local, less car-oriented, and more varied than men's, Law 1999), research on gender and mobility has expanded in diverse directions. These have included the ways in which mobility shapes gender and vice versa (Cresswell and Uteng 2008; Hanson 2010), the male bias in the design of mobility policies (Uteng 2012), gender-related aspects of sustainable mobility (MirallesGuasch, Melo, and Marquet 2016), and the intersection between age and gender inequalities (Murray, Sawchuk, and Jirón 2016; Plyushteva and Schwanen 2018). The significance of theoretical approaches drawing on gender relations has grown further following the 'mobilities turn' in the social sciences, which invited an augmented understanding of observable physical movement, by attending to its relational and multi-faceted nature (Murray, Sawchuk, and Jirón 2016).

Feelings of unsafety are a deeply gendered dimension of mobility, since both forms of violence and forms of fear experienced in the context of the urban night tend to vary significantly by gender, regardless of overall crime rates. At night, women are especially likely to avoid specific routes, bus stops and transport stations if they believe that they may be victimised (Starkweather 2007; Loukaitou-Sideris and Fink 2009). In the Latin American context, research has often focused on women's concerns about verbal or physical assaults, mugging, invasion of their bodily space, and rape (Vargas 2008). Such dangers have been associated with a wide range of urban settings, from open public spaces such as city squares, to parks, streets, and public transport (Macassi 2005). In the context of the Mexico City metro, Soto (2017) has described the ways in which corporeality and the rhythms of public transport are intertwined in the production of fear of sexual assault. Segovia (2009) has traced gendered fear and exclusion in Chile to broader processes of urban fragmentation, through which particular places, such as a local square dominated by groups of young men, can become inaccessible. The interconnections between violence against women, feelings of unsafety, and gendered urban mobilities, have also often been seen as part of the right to the city agenda (Falú 2011; Macassi 2005; Pérez 2019; Vargas 2008).

In the Western European context, too, feeling unsafe can be associated with both crowded and deserted urban spaces. Busy transport spaces are notably associated with groping, while places with few people present, especially at night, are associated with harassment, mugging and theft, and sexual assault and rape (Valentine 1989; Pain 2000; Gilow 2015). In the UK, Lewis, Saukko, and Lumsden (2021) link diurnal rhythms to women's experiences of sexual harassment on the London Underground. Collectiu Punt 6 (2017) demonstrate that feeling unsafe during nocturnal commutes impacts not only women night-shift workers' mobility and routines, but also their health and social relationships. Drawing attention to women's 
individual and collective strategies for dealing with nocturnal unsafety, Sandberg and Coe (2020) have examined the Take Back the Night mobilization in Sweden.

A limited number of prior studies have also addressed women's safety and mobility in our two research locations. In Recife, Siqueira (2015) has explored how fear limits women's access to the urban environment, both during the day and night, emphasising the role of lighting and 'natural surveillance.' In Brussels, Gilow (2015) has demonstrated that feeling unsafe is integral to women's everyday mobility, with gender and class shaping travel behaviour and ways of relating to the city.

\subsection{Comparing urban contexts}

Like much urban research, studies of the challenges faced by women as they navigate the night-time city tend to focus on the global North. Research on women's nocturnal mobilities, while offering a critically important gender perspective on night-time cities, mostly relies on data from London, Paris, New York, and other major Western cities (Schmucki 2012; Schwanen et al. 2012; Smeds, Robin, and McArthur 2020; cf. Parikh 2018; Plyushteva and Boussauw 2020). As a result, not only are the experiences of the inhabitants of Western European and North American cities taken as definitive, but these insights inform the bulk of theory and policy on night-time mobility.

In comparing a Western-European and a Latin-American city, we take inspiration from critical and postcolonial urban and mobilities research, with the aim of disrupting the position of 'paradigmatic' cities (Robinson 2006; Parnell and Robinson 2012; Schwanen 2018) in research on women's mobilities. A comparative lens has the potential to attend to the subtle interplays of gendered relations of im/mobility at night, holding in tension local particularity and experiences which are recognisable across contexts. Comparing two smaller cities across the global South - global North divide does not automatically do away with normative and totalising conceptualisations of women's urban experiences, and like any comparison, risks to amplify such homogenising framings (Robinson 2011). However, our aims in undertaking this comparative exercise are relatively modest, in that rather than generating comprehensive new theories from Brussels and Recife, we a) approach the two cities as valid sources of partial and provisional - empirical and theoretical insights, and b) complicate the ways in which nocturnal mobilities in each of the two cities are conceptualised in relation to each other, and to other cities worldwide. Thus, we attend to local particularity in urban form, transport modes, crime rates, and so on, while at the same time questioning any straightforward attribution of women's experiences to the characteristics of the cities they inhabit.

The lead author's own positionality as a woman who has lived in both cities has played an important role in this respect. Applying a comparative perspective, and doing so with two cities with which we are personally connected, has shaped data collection and interpretation in important ways (Chacko 2004; McDowell 1997). While the paper has benefited from our direct and on-going personal insights into nocturnal mobility in Recife and Brussels, drawing on our own lived experience also presents drawbacks, both because these experiences reflect a position of relative privilege, and because of the possibility of taking for granted that which is familiar (Kern 2005). In relation to addressing the latter, adopting a comparative lens has played a key role in our effort to interrogate familiar settings by examining each in light of the other (Mannay 2010). 


\section{Research locations and methods}

\subsection{Comparing Recife and Brussels}

Recife is the capital of the Brazilian state of Pernambuco, one of the largest cities in the northeast of the country. Brussels is the capital city of Belgium and the administrative centre of the European Union. In 2018, Recife had an estimated population of $1.6 \mathrm{~m}$ inhabitants (IBGE (Instituto Brasileiro de Geografia e Estatística) 2020), compared to the $1.1 \mathrm{~m}$ inhabitants of Brussels. Recife has a surface area equivalent to $219 \mathrm{~km}^{2}$ and a population density of 7,039 inh/ $\mathrm{km}^{2}$ (IBGE (Instituto Brasileiro de Geografia e Estatística) 2020), while the Brussels Capital Region has a surface area of $162 \mathrm{~km}^{2}$ and a density of $7,384 \mathrm{inh} / \mathrm{km}^{2}$ (IBSA (Institut Bruxellois de Statistique et d'Analyse) 2019).

In Recife, many streets are framed by the high walls of the properties along them, especially in the city's wealthier areas. The presence of walls limits the 'eyes on the street' effect and can increase the sense of fear and vulnerability for those outside the walls (Jacobs 1961; Caldeira 2000). In Brussels, relatively more buildings create a connection between private and public space, with ground floors more likely to be orientated towards the pedestrian scale and mixed-use areas (with notable exceptions in the city's central business district). Additionally, both cities host a vibrant night life, especially on weekends.

In Recife, $46 \%$ of all trips are made by public transport, $31 \%$ by private transport, and $23 \%$ use non-motorised modes (Global BRT Data 2020). In Brussels, public transport accounts for a lower $28 \%$ of trips, while a higher share of trips are non-motorised $(40 \%)$, and the share of private transport is comparable at 30\% (SPF Mobilité et transports 2019). The number of cars is growing in Recife, and stable but high in Brussels (DETRAN PE (Departamento Estadual de Trânsito de Pernambuco) 2020; IBSA (Institut Bruxellois de Statistique et d'Analyse) 2019).

Despite extensive public transport networks in both cities, the high reliance on cars reflects low satisfaction with the comfort, reliability, and safety from assault and harassment in public transport. The metropolitan region of Recife has 385 bus lines, which transport 2 million passengers daily. Among them, 42 bus lines operate around-the-clock all week (Pernambuco 2019). Brussels has 82 public transport lines, including bus, tram and metro. Furthermore, eleven bus lines operate on Friday and Saturday night, although frequencies are low, and night lines do not run beyond 3am (STIB. 2019). The Brussels transport authorities have also introduced Collecto, a collective night taxi service that operates every day of the week, from 11 p.m. to 6 a.m. However, the many complexities of booking a Collecto trip mean its popularity is limited (Plyushteva 2019).

\subsection{Methods}

The first part of the data collection involved a questionnaire-based survey, conducted in 2018 and 2019. In total, 397 women responded to the questionnaire, 210 in Recife and 187 in Brussels. In both cities, the questionnaire was distributed via WhatsApp and Facebook groups, complemented by snowball sampling.

To explore individual perceptions, interpretations, and experiences in greater depth, questionnaire respondents were invited to a follow-up semi-structured interview. In total, 
eighteen women were interviewed, ten living in Recife and eight living in Brussels. The sample of respondents reflected a convenience sampling strategy, the social contacts of the lead author, and reliance on WhatsApp and Facebook which, while widely used, are particularly popular among younger people (Statista 2018, 2020). 73\% of questionnaire respondents in Brussels, and 52\% in Recife, were between 19 and 30 years old. The ages of the interviewed women ranged from 20 to 32; most of them were single, with no dependants, and were young professionals or students. The majority of respondents in both Recife and Brussels had more formal education compared to the overall population, with $87 \%$ of respondents in Recife and $91 \%$ in Brussels holding at least a higher education diploma, compared to $19 \%$ and $44 \%$ in the overall population, respectively (PNUD (Programa das Nações Unidas para o Desenvolvimento) 2020; IBSA (Institut Bruxellois de Statistique et d'Analyse) 2019).

Feeling un/safe in the night-time city is shaped by the ways in which social identities such as class, age, ethnicity, sexuality, religion, and bodily capacities, intersect with gender (Pain 2000; Kern 2005; Knox and Pinch 2013; Büscher, Sheller, and Tyfield 2016). It is an important limitation of our study that our sample consists mostly of younger, white women with average or higher incomes. This makes our discussion one of privilege as well as constraint, reflecting intersections of privilege and oppression in the experience of un/safety which we have aimed to make explicit (Pratt and Hanson 1994; Kern 2005). Moreover, the long-standing legal restrictions on collecting ethnicity data in Belgium have been a major impediment to our analysis. A 1962 national law (modified 1 August, 1985) prohibits the National Statistical Institute of Belgium to collect, among others, personal data concerning race and ethnic origin. This statutory ban applies to most demographic data collection and social science research, with the exception of those studies specifically aimed at combatting racial discrimination (see Perrin, Dal, and Poulain 2015).

\section{Results}

\subsection{Mobility at night among women in Brussels and Recife}

Before examining in greater detail the interrelations between nocturnal mobilities and un/safety, we provide an overview of survey respondents' transport modes at night. Figure 1 summarises the modes which respondents reported using either 'always' or 'often' when moving at night. While in Recife women mostly relied on cars or ride-hailing services, in Brussels most respondents used public transport or moved on foot.

Figure 1. Women's transport modes at night in Brussels and Recife. For each mode, the share of respondents answering 'Always' or 'Often' is shown. 


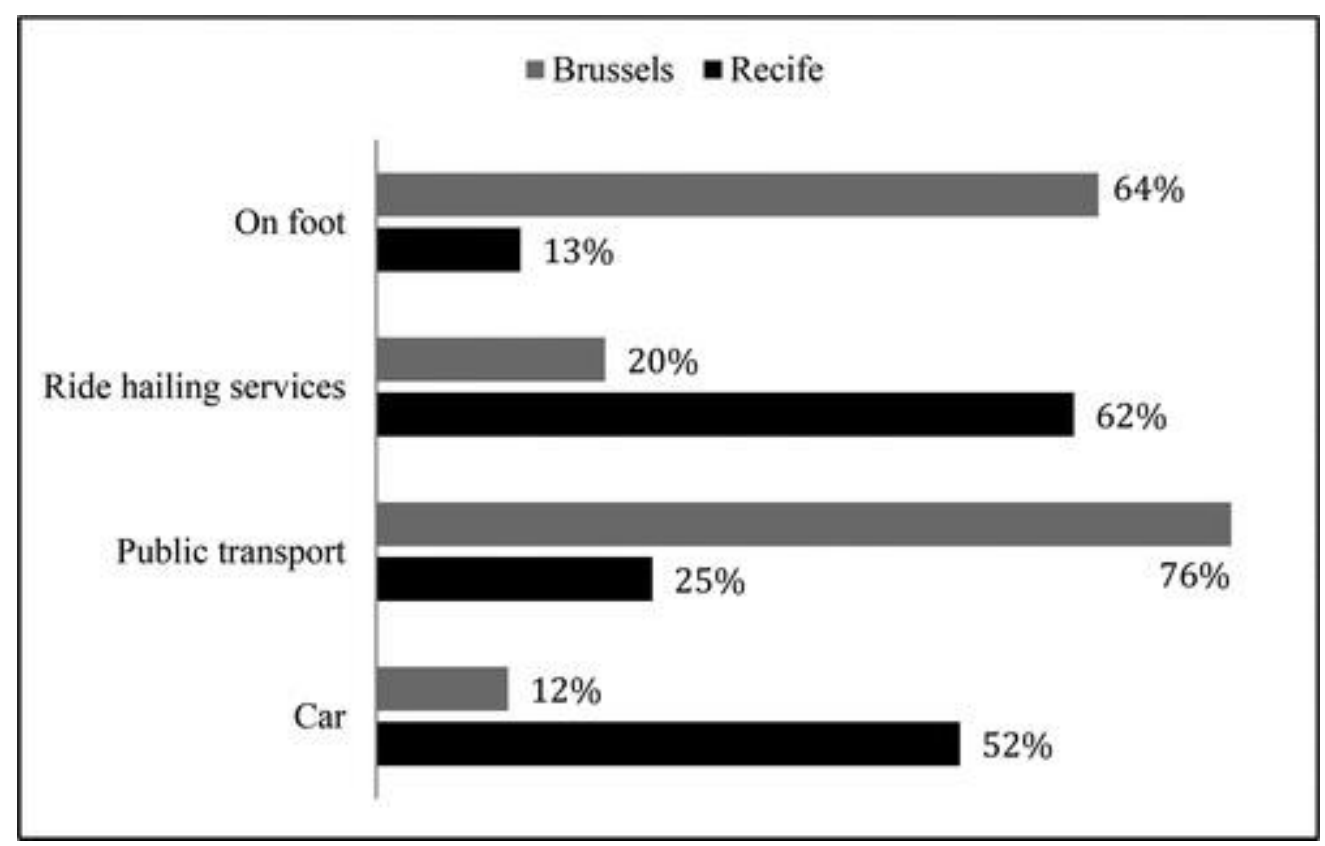

The differences between Brussels and Recife were confirmed by statistical analysis using an unpaired t-test, which showed statistical significance for each of the four transport modes $(\mathrm{p}<0.01)$. Figure 2 summarises the factors which respondents in the two cities identified as most relevant in shaping these divergent night-time mobilities:

Figure 2. Factors influencing women's mobility at night. For each option, the share of respondents choosing 'Very Relevant' is shown.

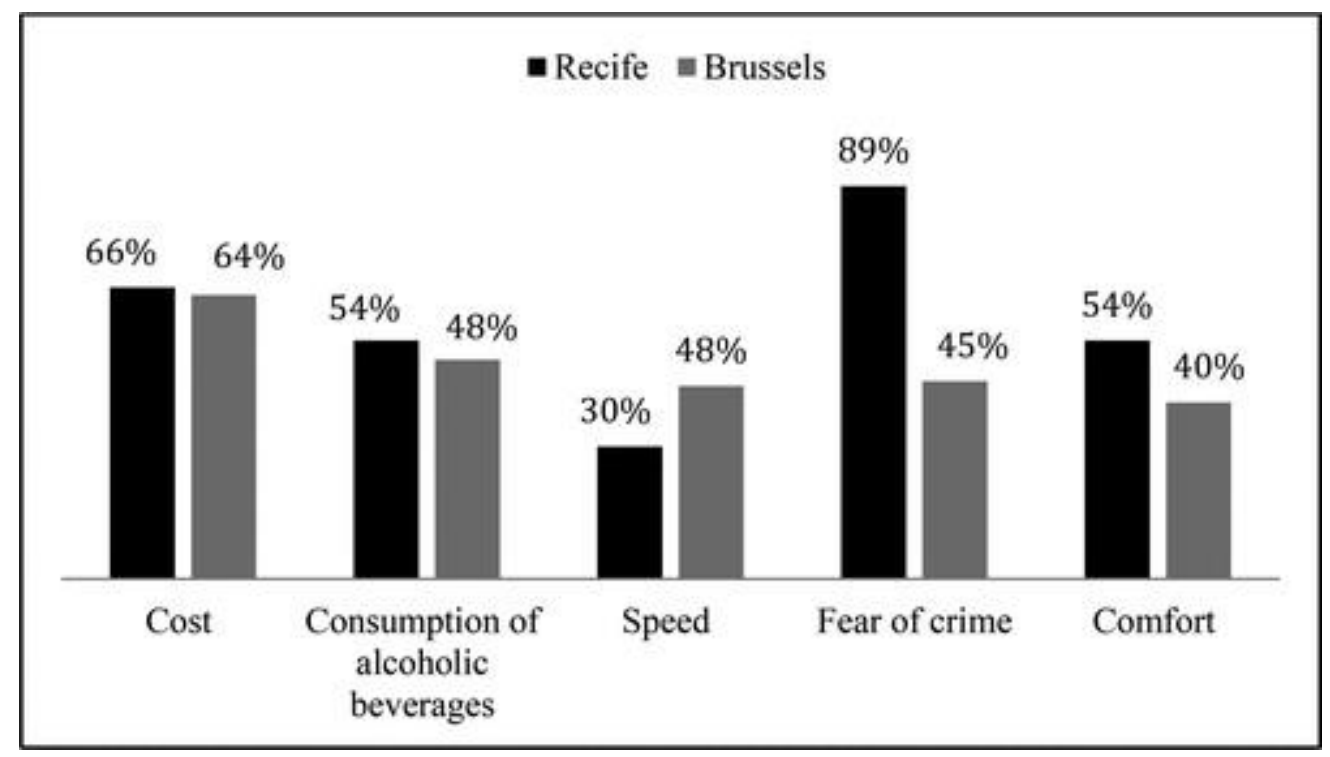

An unpaired t-test was used to verify whether the apparent differences between Recife and Brussels were statistically significant. No substantial differences were found for the variables 'cost' and 'consumption of alcoholic beverages' $(p>0.10)$. With respect to the other variables, differences were confirmed $(\mathrm{p}<0.01)$, but with important variations in the odds ratios. The odds ratios for speed (0.55) and comfort (1.8) were only modest. When it comes to fear of crime, however, the odds ratio of 9.97 indicated a substantial difference between Recife and Brussels. Indeed, the overwhelming majority of respondents in Recife (89\%) 
reported fear of crime as being highly influential in shaping their mobilities at night. In Brussels, $45 \%$ identified this issue as a highly relevant factor. Only $1 \%$ of Recife respondents reported that fear of crime did not affect them at all, while $27 \%$ of women in Brussels claimed not to be influenced by such concerns. Notably, in Recife, $56 \%$ of women said that if they felt safer, their mobility choices at night would be different, e.g. making more journeys on foot, or using public transport.

In the survey element of the research, respondents were asked specifically about fear of crime as a potential reason for feeling unsafe at night. This allowed us to gather answers which were specific and comparable between the two research locations. The issues respondents brought up in the free-text comments box included sexual assault, mugging, and harassment. In the indepth interviews, participants were able to discuss a broader notion of feelings of un/safety beyond the narrower 'fear of crime' concept (regardless of whether criminal behaviour was involved or suspected), while also exploring the interrelationships between factors such as unsafety and cost (see below). Feeling unsafe was a key reason for women in Recife to avoid public transport and walking during the dark hours. For instance, Mariana, 29, argued:

I usually use [ride-hailing app] because I consider it the safest means of transport today and I don't have a car. It [is more cost effective] than the taxi and I consider it safer than public transport. I haven't been on a bus at night for many years. The main reason is not feeling safe. As a woman I'm afraid of both mugging and harassment, I feel more vulnerable, especially at night.

The need to understand nocturnal mobilities in terms of an interplay of safety concerns and cost was emphasised by respondents in both cities. The nuances of the ways in which such considerations shaped mobility together, as trade-offs are reinforcements, could not be captured in the quantitative ranking of factors. In the interviews, Brussels-based respondents placed a relatively greater emphasis on cost, and considerations beyond cost and safety were more likely to be mentioned (e.g. the need to get some fresh air on the way home). Arguably, being less concerned about unsafety allowed more women in Brussels to prioritise a range of different concerns around night-time trips:

I always prefer to walk rather than take the bus; I like to feel the fresh air. Usually, only when it is very cold or when I am very tired I take the bus, besides, I don't feel much safer when I take a bus because I have to walk in another street that is more deserted to get home. (Emma, 22)

Importantly, the relationship between choice of transport mode and feeling fearful, is twodirectional (Grannie 2018). Not only do women choose transport modes which reflect their priorities, concerns, and constraints; in turn, the transport modes they use (by choice or necessity) shape their (feelings of) un/safety. We discuss this in the next section.

\subsection{Situating feelings of unsafety in nocturnal journeys}

The reviewed literature highlights that particular transport modes, or segments of multi-modal journeys (e.g. walking to a bus stop), are often seen by women as particularly unsafe at night (Loukaitou-Sideris and Fink 2009). A high share of women in both cities associated walking after dark with feeling unsafe. In Recife, $95 \%$ of the women surveyed reported feeling unsafe or very unsafe, while in Brussels a lower but still considerable $48 \%$ reported feeling unsafe when on foot. In Brussels in particular, respondents saw inadequate street lighting as key in 
making night-time streets feel threatening. For Amelia, 23, '(...) Brussels is not a well-lit city. Maybe the centre is an exception but I live in a neighbourhood where it can be pretty dark at night. That really makes me feel more insecure.' In Recife, women were more likely to describe walking (or its inaccessibility) in terms of a vicious cycle: because people did not use the streets, others felt discouraged from doing so, resulting in an empty space perceived as less safe (see also Datta and Ahmed 2020, on complicating the notion of better-lit streets as safer streets).

As walking is often needed even when travelling by public transport or bicycle, and to a lesser extent when driving, taking a taxi, or ride-hailing, the vulnerability associated with it is difficult to avoid. Thus, particularly in Recife, the fears associated with moving on foot made pedestrian journeys at night unfeasible for many, but also amplified fears around other modes.

All interviewees discussed feeling safer where other people are present, echoing Jacobs's (1961) famous 'eyes on the street' argument. Importantly, the gender of those present in the space shaped the extent to which the presence of others generated a greater sense of safety. This observation held for both cities. Emma, 22, living in Brussels, observed:

Well-lit places (...) make me feel good at night, as do people passing by on the street, and a balance of presence of men and women. When there are only men, I don't feel very comfortable. But when there are other women in the space, I feel instantly safer.

In Recife, a similar share of respondents rated driving a car as 'unsafe' (38\%) compared to those who rated it 'safe' (29\%). In Brussels, however, 57\% of car drivers reported feeling 'safe' or 'very safe'. During interviews, these results were shown to depend to a great extent on where respondents had to park their car, with the parking of the vehicle and returning to it considered the most unsafe part of the trip. In both cities, driving to leisure destinations after dark generally involved parking in quiet side streets, often chosen over covered parking lots for both proximity and cost. As discussed above, the higher number of pedestrians at night in Brussels generated a degree of safety for drivers as they walked to and from their parked cars. In Recife, interviewees spoke of fearing assault or mugging during these moments. Once inside the vehicle, the feelings of unsafety lessened, as described by Joana, 27:

Driving a car is practical, and I feel safer than when inside a bus. Even though, it is not easy to leave the car on the street; in Recife there is no safety anymore.

However, given concerns about cost, amplified by the high number of students and younger women in our sample (and thus relatively low numbers of car owners), driving oneself at night as a safety strategy was inaccessible for many in both Recife and Brussels. For some, these constraints on nocturnal mobility meant they felt altogether unable to leave their home:

I don't feel safe on the street, I feel very exposed. I avoid going out alone and walking at night for fear of being mugged. Normally, I spend a lot of time at home for that reason because I cannot afford other means of transport and don't drive. (Barbara, 23, Recife)

As demonstrated by Barbara's account, immobility resulting from the combined effects of unaffordability and unsafety defined the experience of a significant number of women. $16 \%$ of respondents in Recife and 3\% in Brussels reported never going out at night due to feeling unsafe. 
In relation to unsafety when using public transport, the quantitative results differed. In Recife, $82 \%$ reported feeling unsafe or very unsafe, while in Brussels a majority felt safe (59\%), yet a large minority of $28 \%$ reported feeling unsafe:

I normally feel safe inside the metro, even if sometimes I receive uncomfortable looks from men. But once in the city centre there was a drunken guy in the last metro at night and I felt insecure. He was talking to me, which made me uncomfortable. I walked away at the first opportunity I had. Even if there were cameras, that didn't change my feeling. (Louise, 24, Brussels)

Brussels inhabitants often referenced the high prevalence of alcohol-related intimidating behaviour on public transport at night. While rarely leading to violence or assault, such encounters created a sense of threat, which was in turn normalised as a result of generally going unchallenged by other passengers. Thus, the provision of night-time public transport services was not in itself sufficient to make women feel safe; a sense of vulnerability could also permeate a space in which 'eyes' were present if intervention was known to be unlikely.

Expectedly, waiting at bus stops and metro stations at night was especially likely to make women feel unsafe. In Recife, 95\% of the participants reported feeling unsafe or very unsafe in such a situation; in Brussels, the share was 69\%. Apart from widespread concerns with lighting, in Brussels, the design and organisation of metro stations was singled out as a factor:

Maybe inside stations things can be done. If something happens and you are lost in a big station it is annoying. Some stations are very big and difficult to go out, you have to validate your ticket also to leave and that takes more time. Maybe a solution would be open them a bit more towards the street, like in Rogier station; that would also make it shorter and easier to leave it. (Louise, 24, Brussels)

These insights are relevant to the organization of public transport spaces, which generally prioritises fare collection, convenience, managing passenger flows, and serving passengers with restricted mobility (Molotch and McClain 2012). Situated and gendered experiences of unsafety should be given greater consideration in transport operators' decision-making, particularly since addressing women's willingness to use public transport outside peak hours reflects multiple policy priorities. These encompass not only accessibility and affordability for women themselves, but also sustainability and farebox takings. Many of these arguments equally apply to our findings regarding women's experiences of bicycling. Respondents in both cities shared reservations about relying on this mode, and highlighted how the shortcomings of cycling infrastructure (poor visibility, uneven surfaces) can acquire a particular significance in relation to night-time safety.

With regard to being in a taxi, Recife responses were almost equally split between feeling unsafe and safe, at $41 \%$ and $38 \%$, respectively. In Brussels, the majority of respondents felt safe or very safe (69\%), and $17 \%$ felt unsafe. However, the relationship between feelings of unsafety and using a transport mode can be complex. For some respondents, taxis represented a significant financial burden, yet they invested in this mode for what they perceived as its relative safety. For women with higher disposable incomes who kept to the wealthy and/or more securitised urban areas, taxis were a matter of comfort and convenience, rather than an investment in feeling less unsafe. These dynamics warrant caution in interpreting the interplay between cost, convenience and safety in terms of straightforward causal links. Furthermore, Amelia, aged 23 and living in Brussels, qualified the notion that taxis are inherently safer: 'I 
have heard so many stories of friends being harassed or assaulted while being in a taxi, that I avoid it; also, it's expensive'. Overall, ride-hailing apps were seen as a safer option, which also benefited from a fixed fare being known in advance, and thus fewer unpleasant or threatening situations arising at the time of paying. The similarity of share of respondents in both cities feeling safe when using ride-hailing apps is notable here, at 52\% in Recife and $66 \%$ in Brussels. Carol (32, Recife), said:

Regarding [ride-hailing app], the advantage is that everything is registered by the application; this gives you more safety than the random taxi you take on the street, for example.

\subsection{Constructing un/safety over the longer term}

Being in a taxi, or a car booked through a ride-hailing app, could be seen as safe or unsafe depending on a number of factors, including past experience:

Whenever I use [a ride-hailing app] I share the location with family members because I've felt very insecure in many rides. I have suffered harassment many times and this made me deeply insecure, so I do all to call less attention (Leticia, 25, Recife).

It is notable from the two contrasting quotes above that feelings of unsafety have multiple temporalities. Events which have happened in the past in more or less similar settings shape how nocturnal un/safety is experienced. While much research focuses on the specific situated and embodied ways in which social identity and built environment (e.g. unlit streets) come together to produce a sense of vulnerability, feeling unsafe is constructed over time and across settings and encounters. Reasons to feel unsafe reflect both one's own and others'

experiences, from family, societal and media discourses (Koskela 1997). It is these temporal dynamics in particular that lead us to question attempts to trace feelings of unsafety to specific antecedents in behaviour or the built environment.

In Recife, $43 \%$ and $30 \%$ of respondents, respectively, had direct experience of mugging and theft, the two most frequently reported types of victimisation. In Brussels, prior experiences of harassment were most commonly reported, at $48 \%$. However, mugging and theft experiences were relatively commonplace also in Brussels, with $20 \%$ and $18 \%$ of women, respectively, having experienced them when mobile at night.

Respondents' in-depth interviews provided insights into the specific ways in which previous situations shaped feelings of unsafety in the present:

I'm from the countryside and coming to [Recife] has given me some traumatic experiences. I've been mugged twice and other colleagues have been too. Also, cases of rape and violence [reported in the media] alert me daily. (Barbara 23, Recife)

I have been mugged twice on the street at night in Brussels. Both times were very close to my house, in places where taking the bus would not have made a difference. When I reported these crimes, the police simply told me there was nothing they could do and were incredibly unsympathetic. (Josephine, 24, Brussels)

Victimisation is not only traumatic in itself, but can generate further fear, directly influencing women's routines, quality of life, and mobility-related decisions (Pain 2001; Starkweather 
2007; Fileborn 2016). Joana (27, Recife) explained how her experience affected her ability to be mobile at night:

After a mugging and attempt of rape at night in my neighbourhood I spent months just going out during the day, at night I was already at home. The therapy helped to go out again at night, but I could only do it alone three months after the incident. Then I went back to a nightly routine, but (...) when I need to go back home alone I prefer to sleep at a friends' place.

Apart from one's own experiences, having relatives or friends who have been victimised also influenced respondents' feelings of vulnerability, as did high-profile media reports:

I'm afraid of rape because some time ago in Recife there were some cases where girls were approached while getting out of the car and taken by the rapist. The street security cameras filmed everything and it was released by the media. I thought it could happen to me too. (Fernanda, 30, Recife)

Narratives of gendered vulnerability are globally recognisable for women, and thus exceed the specifics of transport modes, urban design and crime rates of Recife and Brussels. As Valentine (1989) argues, women's sense of fear is often directly related to traditional notions about the role of women and places considered suitable for them in cities. Many of the narratives around women's presence in the night-time city, its supposed appropriateness in different contexts, and associated risks, had been part of growing up for many respondents in Brussels as well as Recife.

Interview participants negotiated such persistent societal notions of gender-specific vulnerability in diverse and complex ways, internalising, resisting and rethinking the notion of constant danger (Knox and Pinch 2013; Fileborn 2016):

Since my childhood my mother has warned me about the unsafety of walking at night in Recife, so this fear has always been inside me. (Carla, 21, Recife)

This contrasted with the account of Amanda (28, Recife):

The way some men look at a woman in the public space at night fills me with fear and I believe that for a long time this idea was built in my mind that the street was not an environment for me to be alone at night. Currently, I am trying to undo this image of unsafety, but it is hard and a daily work to get me into situations and environments that I did not realise before as belonging to me as well.

We discuss the work which women performed in order to remain mobile at night in the face of feeling unsafe in the next section.

\subsection{Strategies for maintaining mobility at night}

In this final empirical section, we explore the strategies which women draw on in order to counter feelings of unsafety in the night-time city. Examples of strategies can include avoiding certain environments and situations, planning ahead, and coordinating with others (Starkweather 2007; Gilow 2015; Fileborn 2016). Despite the fact that the ways in which 
unsafety was experienced in Recife and Brussels differed, respondents in the two cities reported using similar strategies.

In both cities, women reported taking a longer route home if it allowed them to avoid walking in certain locales. They reported steering clear of narrow, poorly lit streets and deserted places, such as pedestrian underpasses. Clara, 25, in Brussels, described '[choosing] the main roads, instead of some back street'. For, Rose, (20, Brussels), a way of countering a sense of unsafety was moving at greater speed, in particular by opting for the bicycle over moving on foot:

I avoid walking in neighbourhoods where unfortunately I might encounter men who are willing to stalk and harass women. That's why I feel safer to bike, to avoid confrontation.

In both cities, women shared the strategy of being more vigilant and attentive to the surroundings when walking at night. This often included, for instance, removing headphones:

I want to get home as fast as possible; and I am always alert about the environment and who is behind me or around me. I also try not to go to places if I need to think how I am going to get back home, especially after midnight (Amelia, 23, Brussels).

Thus, when out, women performed extensive 'mobility work': they walked faster, avoided remaining stationary, and switched sidewalks when feeling unwanted attention. Such situated strategies of responding to even subtle changes in circumstances are central to many women's management of night-time unsafety. A key insight from in-depth interviews was the extent of advance planning and preparation which women in both cities carried out. Thus, in Brussels, where women were more likely to rely on public transport, several respondents described leaving nights out with plenty of time to spare, in order to not miss the last night bus. For many respondents, preparations for safely returning home started even before leaving the home. The work performed often amounted to arduous efforts: ensuring full phone battery charge (in case of the need for an emergency call, to order a ride-hailing service, or to send messages to relatives and friends informing them of whereabouts), planning a return route when going somewhere less familiar; exploring details of transport schedules, stops and costs; preparing (exact) money; selecting clothes which are enjoyable to wear on a night out, but which would not attract unwanted attention on the way home. Since walking was more prevalent in Brussels, several Brussels-based respondents described also choosing comfortable shoes, which would make it easier to escape from a threatening situation. In both cities, women who walk (some of the way) home at night described avoiding wearing expensive watches or jewellery.

Despite the work respondents invested in preparation for the threats of night-time mobility, a number of women in both Recife and Brussels expressed frustration with the notion that it was up to them to keep themselves safe. As a result, some deployed more 'assertive' strategies. Clara (25, Brussels) talked of taking self-defence classes, and changing her demeanour when walking at night:

If you walk with confidence you show to other people that they should not approach; you send the message that you don't feel vulnerable and you are not an easy target. I also took some self-defence classes which helped me to feel safer. They made me feel more familiar with possible physical conflicts and more confident to defend myself instead of feeling paralysed. 
By contrast, some women felt the only strategy available to them was to avoid the nocturnal journey home altogether, as was the case for Anna (25, Recife), who preferred to sleep at a friend's house instead of returning home alone.

For women who have experienced assault, even seemingly inconsequential situations such as waiting for the traffic lights to turn green could represent a tense moment. However, even among respondents with prior experience of violence (see Joana's account above), many were determined to find ways to participate in nightlife again. This was the case for Leticia (25, Recife):

After I suffered an express kidnapping (from the Portuguese 'sequestro relâmpago'- the victim is held for a few hours under the control of criminals), I look well into the street before stopping at the traffic lights. If I see that the traffic light is red I slow down the vehicle to wait less time. Also, I no longer stay inside a parked vehicle. It is really sad to always be tensed in such moments, but I don't want to stay stuck at home, life goes on.

\section{Discussion and conclusion}

In this paper, we have adopted a comparative approach in exploring the interdependencies between women's un/safety and im/mobility at night. We have sought to build on a long tradition of feminist urban geographies of women's un/safety (Koskela 1997; Mehta and Bondi 1999; Bondi and Rose 2003), extending it to address, and interrogate, the global South - global North binary in research on women's urban mobility. By adopting a comparative and multi-method lens, we have aimed to demonstrate the limits of theorising from a single location and method. Bringing transport and mobility research in conversation with the feminist urban geographies of un/safety, we have problematised the framing of transport modes and spaces in the night-time city as either safe or unsafe (Faria 2017).

The findings reported above demonstrate how the spatial and temporal processes which link specific situations (such as poorly lit streets and deserted underpasses) to construction of feelings and meanings over the longer term (e.g. life-long exposure to warnings from family members), are themselves interconnected with women's experiences of un/safety (Valentine 1989; Pain 2001; Schmucki 2012; Parikh 2018). Our analysis has also highlighted women's work in preparing for and countering unsafety (Fileborn 2016; Gilow 2015). Preparations and precautions place multiple demands on women, such as choosing particular types of clothing, or avoiding direct routes. In this respect, the experiences of respondents in Recife and Brussels have much in common, despite the differences in crime rates, transport provision and urban form in the two cities.

The analysis presented here has a number of important limitations. The respondents whose experiences we draw on are mostly younger, more educated, white, and relatively well-off women from the two cities. At the same time, the ways in which the nocturnal im/mobilities discussed above are both classed and racialised are fundamental to understanding women's experiences in both Recife and Brussels. In this sense, the accounts discussed above reflect a particular intersection of un/safety with privilege, and reported feelings of un/safety at night should be understood in the context of such privilege (to feel belonging in particular nocturnal urban spaces; to assume particular types of im/mobility are available and accessible; see Kern 2005). 
Despite these limitations, this paper has aimed to generate empirical and theoretical insights into two smaller cities which are rarely researched, and even less often included in comparative urban analyses. A number of points can be highlighted as outcomes of this work. First, we have aimed to complicate overarching distinctions between Brussels and Recife's urban nights as intrinsically or homogenously un/safe. Second, and especially as a result of drawing on mixed-method data, we were able to contest simple notions of causality between transport mode 'choices' and feelings of unsafety. Instead, we have considered the interplay between, and continuous renegotiation of, modes, routes, companions, destinations, cost, and feelings of unsafety. Third, we have qualified the idea of the presence of others as a catalyst of feeling safe, particularly in relation to the genders of those present, and the likelihood of them intervening in situations of unwanted attention and harassment.

Finally, acknowledging women's agency in challenging circumstances should not detract from the significant emotional work and economic costs of remaining mobile at night, nor from the experiences of those women who feel immobilised by unsafety. Comparative approaches can make an important contribution in highlighting not only the pervasiveness of women's experiences of unsafety in night-time cities, but also the extent to which women's feeling unsafe can come to be taken for granted, notably in terms of urban policy making. The paper thus has some implications for the governance of mobility and the urban night. For instance, we have identified the importance of clear signage and simple layouts in spaces such as metro stations, facilitating their quick and confident navigation at night. Relatedly, addressing specific safety concerns around walking can have a multiplier effect for safer urban environments at night, since safe pedestrian mobilities are key to reducing feelings of unsafety associated with other modes, for instance in relation to accessing or leaving parked vehicles. More broadly, our findings urge decision-makers to recognise that not acting on unsafety places a disproportionate burden on women in the night-time city, in terms of additional expenditure, extensive advance planning, and the need to restrict and continuously adjust their mobility. We hope that comparative studies such as this one can invite greater understanding of shared challenges among urban authorities in both the global South and global North, and highlight the need for learning from good practice in both directions.

\section{Acknowledgements}

We would like to thank all the women who participated in this research and shared their experiences with us. Many thanks also to the editor and three anonymous reviewers for their feedback, input and guidance.

\section{Disclosure statement}

No potential conflict of interest was reported by the authors.

\section{Additional information}

\section{Notes on contributors}

\section{Leila Farina}


Leila Farina is an architect and urban planner graduated from the Federal University of Pernambuco (2013), Brazil. She holds an MSc in Urban studies from the Vrije Universiteit Brussel (distinction; 2019). Her Master's thesis, which this paper draws on, explored women's perception and experiences of safety affecting mobility habits at night in Brussels, Belgium and Recife, Brazil. Leila's research interests are concerned with gender studies, urban built environment and safety in public spaces.

\section{Kobe Boussauw}

Kobe Boussauw teaches in the MSc in Urban Design and Spatial Planning (STeR*) at the Vrije Universiteit Brussel. His research deals with the reciprocal relationships between mobility, planning, and the built environment, both in an analytical and in a policy oriented sense. Within the first track, the way in which various aspects of spatial structure interact with each other is assessed, whereas in the second track the focus is on decision-making processes that impact on such spatial functioning. Kobe's concern is mainly with the relationship between proximity as a spatial quality, urban livability, and sustainability.

\section{Anna Plyushteva}

Anna Plyushteva is an urban and transport geographer and is a Departmental Research Lecturer in Transport Studies at the School of Geography and the Environment and the Transport Studies Unit, University of Oxford. Her research focuses on urban mobility in terms of daily practices, socio-technical infrastructures, and gendered relations. In her role as Marie Sklodowska-Curie Research Fellow at Cosmopolis (2017-2019), Anna researched commuting in urban shift work in Brussels and Sofia, and night-time mobility in particular. She completed her PhD in Human Geography at University College London (2016), and holds an MSc in International Development Studies (distinction; 2009) from the University of Amsterdam.

\section{References}

- Bianchini, Franco. 1995. "Night Cultures, Night Economies." Planning Practice \& Research 10 (2): 121-126. doi:10.1080/02697459550036667. [Taylor \& Francis Online],

- Bondi, Liz, and Damaris Rose. 2003. "Constructing Gender, Constructing the Urban: A Review of Anglo-American Feminist Urban Geography." Gender, Place and Culture 10 (3): 229-245. doi:10.1080/0966369032000114000.

- Boyce, Peter R., Neil H. Eklund, Bradley J. Hamilton, and Lisa D. Bruno. 2000. "Perceptions of Safety at Night in Different Lighting Conditions." Lighting Research and Technology 32 (2): 79-91. doi:10.1177/096032710003200205.

- Büscher, Monika, Mimi Sheller, and David Tyfield. 2016. "Mobility Intersections: Social Research." Mobilities 11 (4): 485-412. doi:10.1080/17450101.2016.1211818.

- Caldeira, Teresa Pires do Rio. 2000. City of Walls: Crime, Segregation, and Citizenship in São Paulo. Berkeley: University of California Press.

- Chacko, Elizabeth. 2004. "Positionality and Praxis: Fieldwork Experiences in Rural India." Singapore Journal of Tropical Geography 25 (1): 51-63. doi:10.1111/j.01297619.2004.00172.x.

- Collectiu Punt 6. 2017. Nocturnas. The Everyday Life of Women Nightshift Workers in the Barcelona Metropolitan Area. Barcelona: Collectiu Punt 6. 
- Cresswell, Tim, and Tanu Priya Uteng. 2008. "Gendered Mobilities: Towards a Holistic Understanding." In Gendered Mobilities, edited by Tanu Priya Uteng and Tim Cresswell, 1-14. Aldershot: Ashgate.

- Datta, Ayona, and Nabeela Ahmed. 2020. "Intimate Infrastructures: The Rubrics of Gendered Safety and Urban Violence in Kerala, India." Geoforum 110: 67-76. doi:10.1016/j.geoforum.2020.01.016.

- DETRAN PE (Departamento Estadual de Trânsito de Pernambuco) 2020. "Frota de Veiculos." Accessed May 27, 2020. https://www.detran.pe.gov.br

- Eldridge, Adam, and Marion Roberts. 2008. "A Comfortable Night Out? Alcohol, Drunkenness and Inclusive Town Centres.” Area 40 (3): 365-374. doi:10.1111/j.14754762.2008.00813.x.

- Falú, Ana. 2011. "Restricciones ciudadanas: Las violencias de género en el espacio público." Pensamiento Iberoamericano 9: 127-146.

- Faria, Caroline. 2017. "Towards a Countertopography of Intimate War: Contouring Violence and Resistance in a South Sudanese Diaspora." Gender, Place and Culture 24 (4): 575-593. doi:10.1080/0966369X.2017.1314941.

- Fileborn, Bianca. 2016. “Doing Gender, Doing Safety? Young Adults' Production of Safety on a Night out." Gender, Place and Culture 23 (8): 1107-1120. doi:10.1080/0966369X.2015.1090413.

- Gilow, Marie. 2015. “Travelling in Brussels and Feeling Unsafe: Women's Perceptions and Strategies.” Brussels Studies 87: 1277 http://brussels.revues.org/1277. doi:10.4000/brussels.1277.

- Global BRT Data. 2020. “Report Recife, Brazil.” Accessed May 28, 2020. https://brtdata.org/location/latin_america/brazil/recife

- Grannie, Marie-Axelle. 2018. "Transport, Mobility and Security: A Matter of Gender.” In International Transport Forum Women's Safety and Security: A Public Transport Priority. Paris: OECD Publishing.

- Hanson, Susan. 2010. "Gender and Mobility: New Approaches for Informing Sustainability.” Gender, Place and Culture 17 (1): 5-23. doi:10.1080/09663690903498225.

- IBGE (Instituto Brasileiro de Geografia e Estatística). 2020. "Cidades e Estados. Recife." Accessed March 8, 2021. https://www.ibge.gov.br/cidades-e-estados/pe/recife.html

- IBSA (Institut Bruxellois de Statistique et d'Analyse). 2019. "Mini-Bru 2019. La Région de Bruxelles-Capitale en chiffres." Report, Accessed August 8, 2019. http://ibsa.brussels/fichiers/publications/minibru/mini-bru_2019_fr

- Jacobs, Jane. 1961. The Death and Life of Great American Cities. New York: Random House.

- Jirón, Paola, Juan-Antonio Carrasco, and Marcela Rebolledo. 2020. “Observing Gendered Interdependent Mobility Barriers Using an Ethnographic and Time Use Approach.” Transportation Research Part A: Policy and Practice 140: 204-214. doi:10.1016/j.tra.2020.08.018.

- Kern, Leslie. 2005. "In Place and at Home in the City: Connecting Privilege, Safety and Belonging for Women in Toronto." Gender, Place and Culture 12 (3): 3, 357-377. doi:10.1080/09663690500202590.

- Knox, Paul, and Steven Pinch. 2013. "Bodies, Sexuality and the City." In Urban Social Geography: An Introduction, edited by Paul Knox and Steven Pinch, 234-251. Edinburgh: Pearson.

- Koskela, Hille. 1997. “Bold Walk and Breakings': Women's Spatial Confidence versus Fear of Violence." Gender, Place and Culture 4 (3): 301-319. doi:10.1080/09663699725369. 
- Law, Robin. 1999. "Beyond "Women and Transport": Towards New Geographies of Gender and Daily Mobility." Progress in Human Geography 23 (4): 567-588. doi:10.1191/030913299666161864.

- Lewis, Sian, Paula Saukko, and Karen Lumsden. 2021. "Rhythms, Sociabilities and Transience of Sexual Harassment in Transport: Mobilities Perspectives of the London Underground." Gender, Place and Culture, 28 (2): 277-298. doi:10.1080/0966369X.2020.1734540.

- Loukaitou-Sideris, Anastasia, and Camille Fink. 2009. "Addressing Women's Fear of Victimization in Transportation Settings: A Survey of U.S. Transit Agencies." Urban Affairs Review 44 (4): 554-587. doi:10.1177/1078087408322874.

- Macassi, Ivonne, ed. 2005. El miedo a la calle: la seguridad de las mujeres en la ciudad. Lima: Centro de la Mujer Peruana Flora Tristán.

- Mannay, Dawn. 2010. "Making the Familiar Strange: Can Visual Research Methods Render the Familiar Setting More Perceptible?" Qualitative Research 10 (1): 91-111. doi:10.1177/1468794109348684.

- McDowell, Linda. 1997. "Women/Gender/Feminisms: Doing Feminist Geography." Journal of Geography in Higher Education 21 (3): 381-400. doi:10.1080/03098269708725444.

- Mehta, Anna, and Liz Bondi. 1999. "Embodied Discourse: On Gender and Fear of Violence." Gender, Place and Culture 6 (1): 67-84. doi:10.1080/09663699925150.

- Miralles-Guasch, Carme, Montserrat Martínez Melo, and Oriol Marquet. 2016. "A Gender Analysis of Everyday Mobility in Urban and Rural Territories: From Challenges to Sustainability." Gender, Place and Culture 23 (3): 398-417.

- Molotch, Harvey, and Noah McClain. 2012. "Below the Subway: Taking Care Day in and Day Out." In Against Security: How We Go Wrong at Airports, Subways, and Other Sites of Ambiguous Danger, edited by Harvey Molotch, 50-84. Princeton, NJ: Princeton University Press.

- Murray, Lesley, Kim Sawchuk, and Paola Jirón. 2016. "Comparative Mobilities in an Unequal World: Researching Intersections of Gender and Generation.” Mobilities 11 (4): 542-552. doi:10.1080/17450101.2016.1211822.

- Pain, Rachel. 2000. "Place, Social Relations and the Fear of Crime: A Review." Progress in Human Geography 24 (3): 365-387. doi:10.1191/030913200701540474.

- Pain, Rachel. 2001. "Gender, Race, Age and Fear in the City." Urban Studies 38 (5-6): 899-913. doi:10.1080/00420980120046590.

- Parikh, Aparna. 2018. "Politics of Presence: Women's Safety and Respectability at Night in Mumbai, India." Gender, Place and Culture 25 (5): 695-710. doi:10.1080/0966369X.2017.1400951.

- Parnell, Susan, and Jennifer Robinson. 2012. “(Re)Theorizing Cities from the Global South: Looking beyond Neoliberalism.” Urban Geography 33 (4): 593-617. doi:10.2747/0272-3638.33.4.593.

- Pérez, Gabriel. 2019. "Políticas de movilidad y consideraciones de género en América Latina.” Serie Comercio Internacional, 152 (LC/TS.2019/108), Santiago: Comisión Económica para América Latina y el Caribe (CEPAL).

- Pernambuco. 2019. "Dados e estatísticas." Grande Recife Consórcio de transportes. Accessed May 27, 2020. http://www.granderecife.pe.gov.br/sitegrctm/transporte/dados-eestatisticas/

- Perrin, Nicolas, Luc Dal, and Michel Poulain. 2015. "The Objective Approaches of Ethnic Origins in Belgium: Methodological Alternatives and Statistical Implications." In Social Statistics and Ethnic Diversity Cross-National Perspectives in Classifications and Identity Politics, edited by Patrick Simon, 191-208. London: Springer. 
- Plyushteva, Anna. 2019. "Commuting and the Urban Night: Nocturnal Mobilities in Tourism and Hospitality Work." Journal of Policy Research in Tourism, Leisure and Events 11 (3): 407-421. doi:10.1080/19407963.2018.1556673.

- Plyushteva, Anna, and Kobe Boussauw. 2020. "Does Night-Time Public Transport Contribute to Inclusive Night Mobility? Exploring Sofia's Night Bus Network from a Gender Perspective." Transport Policy 87: 41-50. doi:10.1016/j.tranpol.2020.01.002.

- Plyushteva, Anna, and Tim Schwanen. 2018. "Care-Related Journeys over the LifeCourse: Thinking Mobility Biographies with Gender, Care and the Household." Geoforum 97: 131-141. doi:10.1016/j.geoforum.2018.10.025.

- PNUD (Programa das Nações Unidas para o Desenvolvimento). 2020. "Recife-PE: Escolaridade da população adulta 2010." Atlas do Desenvolvimento Humano no Brasil. Accessed March 8, 2021. http://www.atlasbrasil.org.br/perfil/municipio/261160

- Pratt, Geraldine, and Susan Hanson. 1994. "Geography and the Construction of Difference." Gender, Place and Culture 1 (1): 5-29. doi:10.1080/09663699408721198.

- Robinson, Jennifer. 2006. Ordinary Cities: Between Modernity and Development. London: Routledge.

- Robinson, Jennifer. 2011. “Comparisons: Colonial or Cosmopolitan?” Singapore Journal of Tropical Geography 32 (2): 125-140. doi:10.1111/j.1467-9493.2011.00423.x.

- Sandberg, Linda, and Anna-Britt Coe. 2020. "Taking Back the Swedish Night: Making and Reclaiming Space.” Gender, Place and Culture 27 (7): 1044-1062. doi:10.1080/0966369X.2019.1693339.

- Schmucki, Barbara. 2012. "If I Walked on my Own at Night I Stuck to Well Lit Areas." Gendered Spaces and Urban Transport in 20th Century Britain." Research in Transportation Economics 34 (1): 74-85. doi:10.1016/j.retrec.2011.12.002.

- Schwanen, Tim. 2018. "Geographies of Transport III: New Spatialities of Knowledge Production?" Progress in Human Geography 42 (3): 463-472. doi:10.1177/0309132517699925.

- Schwanen, Tim, Irina van Aalst, Jelle Brands, and Tjerk Timan. 2012. "Rhythms of the Night: Spatiotemporal Inequalities in the Nighttime Economy." Environment and Planning A: Economy and Space 44 (9): 2064-2085. doi:10.1068/a44494.

- Segovia, Olga. 2009. "Convivencia en la diversidad: una mirada de género al espacio público." In Mujeres en la Ciudad: De violencias y derechos, edited by Ana Falu, 145162. Santiago: Red Mujer y Hábitat de América Latina Ediciones SUR.

- Shaw, Robert. 2014. "Beyond Night-Time Economy: Affective Atmospheres of the Urban Night." Geoforum 51 (1): 87-95. doi:10.1016/j.geoforum.2013.10.005.

- Siqueira, Lucia. 2015. "Por onde andam as mulheres: percursos e medos que limitam a experiência de mulheres no centro do Recife.” M.A. thesis, Federal University of Pernambuco.

- Smeds, Emilia, Enora Robin, and Jenny McArthur. 2020. "Night-Time Mobilities and (in) Justice in London: Constructing Mobile Subjects and the Politics of Difference in PolicyMaking." Journal of Transport Geography 82: 102569. doi:10.1016/j.jtrangeo.2019.102569.

- Soto, Paula. 2017. "Diferencias de género en la movilidad urbana. Las experiencias de viaje de las mujeres en el Metro de la Ciudad de México." Revista Transporte y Territorio 16: 127-146.

- SPF Mobilité et transports. 2019. Enquête Monitor sur la mobilité des Belges. Accessed May 27, 2020. https://mobilit.belgium.be/sites/default/files/partie_mobilite_novembre_2019_final.pdf 
- Starkweather, Sarah. 2007. "Gender, Perceptions of Safety and Strategic Responses among Ohio University Students." Gender, Place and Culture 14 (3): 355-370. doi:10.1080/09663690701325000.

- Statista. 2018. "Share of WhatsApp Users in Latin America in 2018, by Age." Accessed June 4, 2020. https://www.statista.com/statistics/754370/latin-america-usage-penetrationwhatsapp-age/

- Statista. 2020. "Distribution of Facebook Users Worldwide as of April 2020, by Age and Gender.” Accessed June 4, 2020. https://www.statista.com/statistics/376128/facebookglobal-user-age-distribution/

- $\quad$ STIB. 2019. “Activity Report.” Accessed August 10, 2019. http://2018.stibactivityreports.brussels/en

- Uteng, Tanu Priya. 2012. Gender and Mobility in the Developing World. Washington, DC: World Bank.

- Valentine, Gill. 1989. “The Geography of Women's Fear.” Area 21 (4): 385-390.,

- van Liempt, Ilse. 2015. "Safe Nightlife Collaborations: Multiple Actors, Conflicting Interests and Different Power Distributions." Urban Studies 52 (3): 486-500. doi:10.1177/0042098013504010.

- Vargas, Virginia. 2008. Programa Regional Ciudades sub Violencia hacia las Mujeres, Ciudades Seguras para Todas y Todos. Brasília: UNIFEM Brasil y países del Cono Sur.

- Williams, Robert. 2008. "Night Spaces: Darkness, Deterritorialization, and Social Control." Space and Culture 11 (4): 514-532. doi:10.1177/1206331208320117.

- Wilson, Elizabeth. 2001. "The Invisible Flaneur (Revised Version)." In The Contradictions of Culture: Cities, Culture, Women, edited by Elizabeth Wilson, 72-89. London: Sage. 